\title{
MAPPING OF SARGASSUM DISTRIBUTION IN THE EASTERN COAST OF SOUTHERN LEYTE USING SENTINEL 2 SATELLITE IMAGERY
}

\author{
J. J. Lasquites ${ }^{1}$, A. Blanco ${ }^{2}$, A. Tamondong ${ }^{2}$ \\ ${ }^{1}$ Department of Geodetic Engineering, College of Engineering, Visayas State University, Baybay City, Leyte, Philippines - \\ jjslasquites@gmail.com \\ ${ }^{2}$ Department of Geodetic Engineering, College of Engineering, University of the Philippines Diliman - acblanco@up.edu.ph, \\ amtamondong@up.edu.ph
}

\section{Commission IV}

KEY WORDS: Sargassum Distribution, Supervised Classification, Geostatistical Analysis, Coastal Resource Mapping, Sentinel 2, Remote Sensing

\begin{abstract}
:
Sargassum is a brown seaweed distributed in the Philippines and recognized as an additional source of income for fishing communities. Due to uncontrolled harvesting of the seaweed, the Department of Agriculture regulated its collection and harvesting by imposing seasonal restrictions. Hence, the need to identify the locations and cover of healthy Sargassum is vital to address the demand in the market while maintaining ecological balance in the marine ecosystem. Two Sentinel-2 satellite imagery (10 m resolution) acquired on December 08, 2017 (peak growth) and May 27, 2018 (senescence stage) were used to map the presence of Sargassum in the eastern coast of Southern Leyte. Supervised classification using maximum likelihood algorithm and accuracy assessment were conducted before generating the map. Three classes were considered namely Sargassum, clouds and land. Furthermore, Anselin Local Moran's I (cluster and outlier analysis) was conducted to determine which areas have significant clustering of "healthy" Sargassum using the normalized difference vegetation index (NDVI). For both image dates, high classification accuracies of Sargassum were obtained in the islands. However, there are misclassifications of Sargassum in Silago $(\mathrm{UA}=78.72 \%)$ and Hinunangan $(\mathrm{PA}=82.35 \%)$ using the May image. Furthermore, misclassification of Sargassum were obtained in Silago $(\mathrm{PA}=93.6 \%)$ and Hinundayan $(\mathrm{PA}=96.23 \%)$ using the December image. Clusters of high NDVI values are more evident in December. Healthy Sargassum are apparent in the coast of Silago and mostly found near shore and in rocky substrates.
\end{abstract}

\section{INTRODUCTION}

\subsection{Background of the Study}

The genus Sargassum is one of the important brown seaweeds that is distributed in temperate and tropical oceans. It is utilized as animal feed, fertilizer, and as source of alginate which has various industrial uses. It is also a promising raw material for ethanol production because of its relatively high content of holocellulose (Tamayo and Del Rosario 2014). Furthermore, it provides food, refuge and breeding grounds for fish, sea turtles, marine birds, crabs, shrimps and more.

Asian countries such as Japan, China, and Korea use Sargassum for human consumption as sea vegetables and as medicinal "seaweed herbs" for bronchitis, laryngitis, hypertension, infections, fever, and goiter (Hou and Jin 2005). The seaweed grows on rocks, boulders and hard substrata (Baweja, et al. 2016). Environmental variables such as sea temperature, light, wind-driven upwelling and wave height are previously linked to seaweed seasonality (Fulton, et al. 2014).

The Philippines, home to one of the most diverse Sargassum resources in the western Pacific basin, has more than 40 species of Sargassum. They have been recognized as additional sources of income for the fishing communities in the country. Sargassum productions in Central Visayas are exported to Japan while those in Northern Mindanao are utilized in the local manufacture of feeds (Trono Jr., G.C., 1990).

Due to its high commercial value (US $\$ 460$ per wet ton) and demand in both local and global market, harvesting of Sargassum became uncontrolled. The balance in marine ecosystem was altered resulting in loss of shelter and food to many aquatic organisms dependent of the seaweed. Hence, the Philippines' Department of Agriculture (DA) issued Fisheries Administrative Order No. 250, series of 2014, Prohibiting the Collection, Harvesting, Gathering, Selling and/or Exporting of Brown Algae (Sargassum spp.) and Seagrass. Recently, it was amended, allowing individual fishermen to collect, sell, trade, and transport Sargassum subject to seasonal restrictions and permit requirements (FAO 250-2 series of 2017). Therefore, the need to identify the locations and cover of healthy Sargassum is vital to address the demand in the market while maintaining ecological balance in the marine ecosystem.

A number of researches has used satellite remote sensing for marine and coastal resource mapping which includes seaweed (Siddiqui and Zaidi 2015). Studies conducted for brown algal mapping specifically Sargassum used satellite images such SPOT (Satellite Pour l'Observation de la Terre), Landsat, Quickbird, MERIS (Medium Resolution Imaging Spectrometer), ALOS AVNIR-2 and MODIS (Moderate Resolution Imaging Spectroradiometer). Belsher et al. (1990) used SPOT (15 m resolution) satellite images to study the distribution of Sargassum muticum in Moorea Island. In 2008, Mattio et. al used Landsat 7 (30 m resolution) and Quickbird ( $2.4 \mathrm{~m}$ resolution), a high resolution commercial satellite to determine the coverage of Sargassum beds in South West Lagoon, New Caledonia. Moreover, MERIS (300 m resolution) observation was conducted to document the Sargassum distributions and abundance in the Intra-Americas Sea and central Atlantic from 2002 to 2011 (Gower \& King, 2011; Gower et al., 2013). However, MERIS stopped functioning in 2012 hence MODIS alternative floating algae index (AFAI) was used to continually monitor the distribution of the seaweed in the Caribbean, the greater Intra-Americas 
Sea and nearby oceans (Wang and Hu 2016). Aside from that, MODIS Aqua with $1 \mathrm{~km}$ spatial resolution was also used to detect Sargassum presence and quantified its coverage (Adet, et al. 2018). The need to have an accurately mapped Sargassum beds led Noiraksar et al. (2014) to use ALOS AVNIR-2 (10 m resolution) satellite imagery in the coast of Chon Buri Province, Thailand. In 2015, the European Space Agency launched Sentinel-2 (10 m resolution) satellite, a provider of free satellite images which covers all Earth's land surfaces, large islands, inland and coastal waters gave opportunities for Sargassum mapping. This study, therefore aimed to use Sentinel-2 satellite imagery to map the distribution and cover of Sargassum in the Eastern Coast of Southern Leyte. Furthermore, geostatistical analysis was conducted to determine the locations of healthy Sargassum within the study area as a tool for Sargassum resource management.

\subsection{Study Area}

The study area covered the coasts of Silago, Hinunangan, Hinundayan, and the two islands of San Pedro and San Pablo in the province of Southern Leyte, Philippines (Figure 1). However, the study area limits its extent to $500 \mathrm{~m}$ offshore due to the inability of the seaweed to grow beyond the set distance. The coastline of these municipalities were used as the study area because, naturally growing Sargassum are present in the area. Furthermore, as seen in the satellite imagery and during reconnaissance this naturally growing Sargassum are found mostly in rocky substrates. The extent of rocky substrates from the shoreline to offshore was around $500 \mathrm{~m}$ as measured using Google Earth.

The coastal municipalities of Silago, Hinunangan and Hinundayan have ebony beaches with unique black to brown sand. Tidal flats and rock cliffs are also found in Silago and Hinundayan. However, Hinunangan has improved its tourism industry due to its beautiful white sand beaches in the islands of San Pedro and San Pablo. These municipalities are abundant with marine resources including coral reefs, mangroves, sea grasses and seaweeds. In addition, ten (10) Marine Protected Areas (MPAs) are found within the coast of these municipalities.

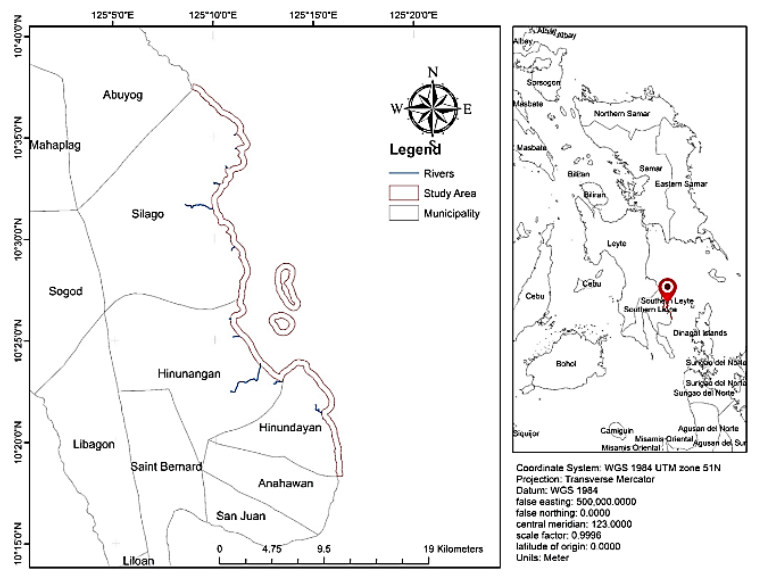

Figure 1. Location of the study area along the east coast of Southern Leyte, Philippines

\section{METHODOLOGY}

\subsection{Preprocessing}

Sargassum reach peak growth during December and its senescence stage occur around May (Montes Jr 1993). Hence, two (2) Sentinel-2 satellite images with $10 \mathrm{~m}$ resolution were used to map the presence of Sargassum in the area. These data were remotely sensed on May 27, 2018 and December 08, 2017. The data were then preprocessed applying Top Of Atmosphere (TOA) reflectance using the Semi-Automatic Classification Plugin of QGIS. TOA reflectance is a combined surface and atmospheric reflectance in order to reduce the in between-scene variability through a normalization for solar irradiance (Congedo 2016). For Sentinel-2 images TOA reflectance are already provided together with its raw data. Furthermore, Dark Object Subtraction (DOS), another imagebased atmospheric correction was employed. DOS considered those pixels covered with shadows have radiance from atmospheric scattering (Congedo 2016). The images were then clipped to the extent of the study area. Sentinel images were enhanced to visibly distinguish seaweed from other features using histogram equalization tool in ENVI. Image enhancement was done by adjusting intensities/contrasts of digital images for a more suitable display or for further image analysis (Dorothy, et al. 2015)

\subsection{Supervised Classification}

To extract Sargassum, supervised classification using maximum likelihood algorithm was done. In supervised classification, the image analyst specifies spectral signatures that should be associated with each class. This was done by collecting training areas or Regions of Interest (ROIs). The computer algorithm then uses the spectral signatures to classify the whole image (Humboldt State Geospatial Online 2019). Classification dealt with three classes (1) area covered with Sargassum, (2) clouds and (3) land. Though Class (1) was used for further analysis, the presence of clouds covering the coastal area where Sargassum are possibly growing was also indicated. Land was extracted to emphasize that this seaweeds are found in coastal areas.

\subsection{Accuracy Assessment}

Accuracy assessment was done before generating the map to compare the classified image to ground truth data. Hence, the locations of Sargassum obtained during field observation were used to validate the classified image (Figure 2). Both training and validation ROIs were distributed within the study area. There were thirty-three (33) training ROIs and thirty-two (32) validation ROIs. In accuracy assessment, overall accuracy (OA) and Kappa coefficient $(\mathrm{KC})$ were computed. If the overall accuracy is low, checking on the spectral signature of the training ROIs was needed. Making sure that the training ROIs of a specific class have the same spectral signature. A value of one (1) for the Kappa coefficient generates a good classified image. Moreover, the confusion matrix determines which features are correctly classified and which are not. Error of commission (EC) determines the amount of pixels (expressed in percentage) that were classified as Sargassum when in reality, it is not. While error of omission (EO) is when a certain pixel is classified as Rock (other feature) when in fact it is a Sargassum. These errors were used as guide to locate pixels that were classified incorrectly.

In order to generate a map showing the location of Sargassum, output polygon vector produced by class (1) and 
class (2) were used. Aside from the polygon vector covered by the Sargassum, presence of clouds was also shown in the map. Hence, it is uncertain if Sargassum exist or does not exist in the area.

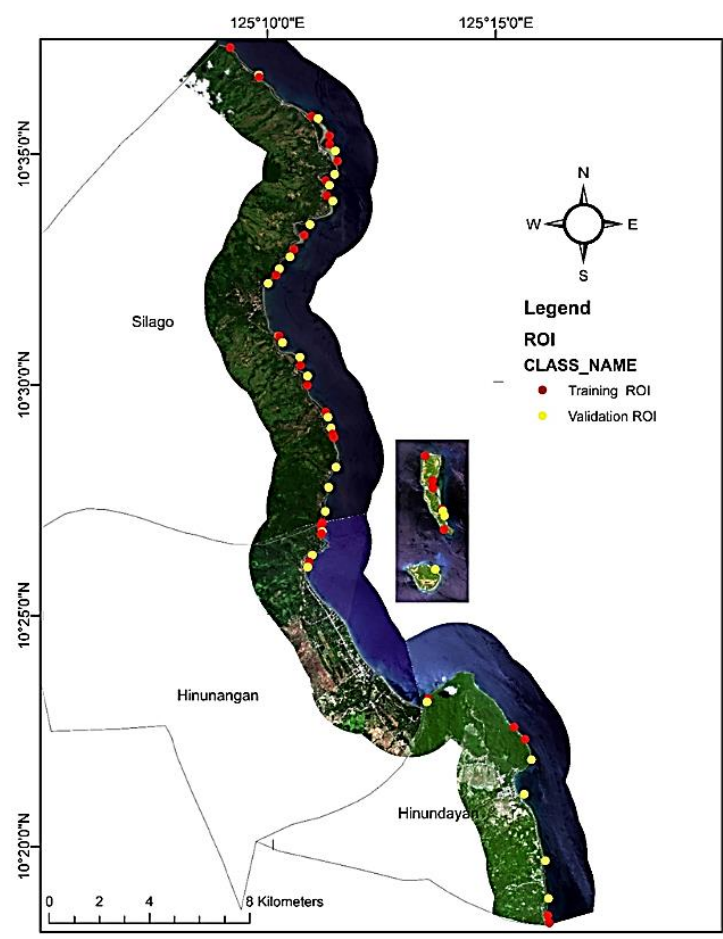

Figure 2. Locations of training and validation ROIs

\subsection{Geostatistical Analysis}

Geostatistical analysis specifically Anselin Local Moran's I (cluster and outlier analysis) was done to determine which areas have clustering of healthy Sargassum. The analysis identifies spatial clusters of features with high or low values. Furthermore, spatial outliers where features are randomly distributed in the area were indicated (Esri 2018). Locations of clustering of high and low values were used in generating the suitability map for Sargassum mariculture. The Class 1 polygon vectors obtained from supervised classification were used as clipping files to create subset of each satellite images (May and December 2017).

The normalize difference vegetation index (NDVI) is being used widely to estimate vegetation extent, biomass and productivity including coastal plants which are essential for underwater habitat studies (Siddiqui and Zaidi 2015). Hence, NDVI was used to determine vegetation "health" of the seaweed. It was calculated using the equation (NIR - Red) / (NIR + Red) where NIR and Red are reflectance values in bands 8 and 4 of Sentinel 2 image. These raster images were converted to point vector wherein each point corresponds to a specific NDVI value. To determine the ideal threshold value for cluster and outlier analysis, Incremental Spatial Autocorrelation was implemented. It measures spatial autocorrelation for a series of distances and shows their corresponding standard deviations (z-scores). Significant peak of z-score corresponding to a certain distance indicates that the clustering is very evident. Anselin Local Moran's I (Cluster and outlier analysis) is a tool that distinguishes between statistically significant cluster of high values (high-high), cluster of low values (low-low) and outlier wherein a high value is surrounded primarily with low values and vice versa (Esri 2018).

In cluster and outlier analysis, local Moran's I (index) value, $\mathrm{z}$-score, p-value and a code representing the cluster type for each statistically significant features were determined. A positive value of I indicates similarly high or low neighboring values. While dissimilar neighboring features obtained a negative value of I which are also considered as outliers. Furthermore, local Moran' I is a relative measure and can only be interpreted with the z-score and p-value. The p-value is a probability while $\mathrm{z}$-score are standard deviations. Thus, very high or very low (negative) z-score with very small p-value indicates clustering of similar values. High positive value of $\mathrm{z}$-score and a small p-value connotes clustering of high values (high-high). On the other hand, clustering of low (low-low) values are represented with low negative $\mathrm{z}$-score with low $\mathrm{p}$ value (Esri 2018).

\section{RESULTS AND DISCUSSION}

During image classification, Regions of Interest (ROIs) were carefully selected based on the spectral profile. Figure 3 shows the spectral profile of Sargassum from both satellite images (May and December). There was difficulty in identifying a certain pixel whether it is a rock or a Sargassum since both features look similar in the satellite image. Hence, their spectral profiles were determined and collected for image classification. Figure 4 shows the spectral profile of Sargassum (Class 1) compared to rock (Class 3 ).

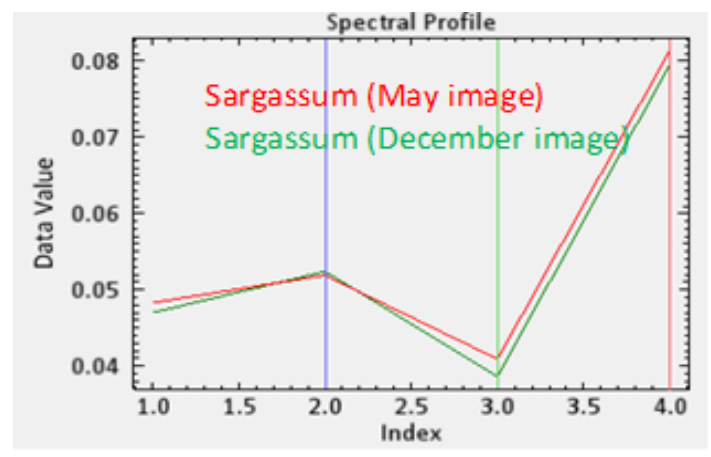

Figure 3. Spectral profile of Sargassum

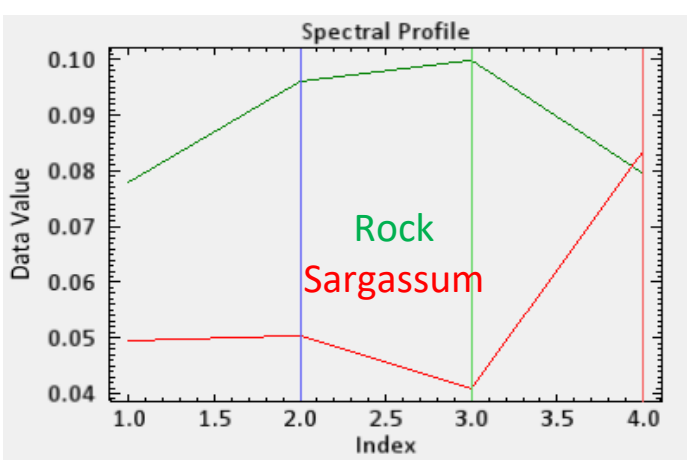

Figure 4. Spectral profile of the seaweed and rock 
Table 1 shows the results from the accuracy assessment of both images. There are 133 pixels out of 625 pixels in Silago area that were classified as Sargassum when in reality, it is not. Hence resulted to $21.28 \%$ error of commission (EC). These pixels were located in Sabang river. Furthermore, there is $17.65 \%$ error of omission (EO) in Hinunangan area wherein pixels that were classified as other feature is in fact a Sargassum. This is due to the sporadic distribution of Sargassum in the area. Therefore, misclassification of Sargassum in Silago and Hinunangan using the May image resulted to low User's (UA) and Producer's (PA) Accuracies of $78.72 \%$ and $82.35 \%$, respectively. Minimal errors were obtained using the December image hence resulted to PA and UA ranging from $93.6 \%$ to $100 \%$. Though misclassification of Sargassum were present, high percentage of overall accuracy (OA) were obtained in both images.

Table 1. Classification accuracy of: (A) May Sentinel-2 image and (B) December Sentinel-2 image

\begin{tabular}{|c|c|c|c|c|c|c|c|}
\hline \multicolumn{8}{|c|}{ A. SENTINEL 2 IMAGE DURING MAY } \\
\hline Region & Class & $\begin{array}{l}\text { EC } \\
(\%)\end{array}$ & $\begin{array}{l}\text { EO } \\
(\%)\end{array}$ & $\begin{array}{l}\text { PA } \\
(\%)\end{array}$ & $\begin{array}{l}\text { UA } \\
(\%)\end{array}$ & $\begin{array}{l}\text { OA } \\
(\%)\end{array}$ & $\mathrm{KC}$ \\
\hline \multirow[b]{2}{*}{ Silago } & Sargassum & 21.28 & 0 & 100 & 78.72 & \multirow[b]{2}{*}{99.94} & \multirow[b]{2}{*}{0.88} \\
\hline & $\begin{array}{l}\text { Other } \\
\text { Features }\end{array}$ & 0 & 0.06 & 99.94 & 100 & & \\
\hline \multirow[b]{2}{*}{ Hinunangan } & Sargassum & 0 & 17.65 & 82.35 & 100 & \multirow[b]{2}{*}{99.99} & \multirow[b]{2}{*}{0.83} \\
\hline & $\begin{array}{l}\text { Other } \\
\text { Features }\end{array}$ & 0 & 0 & 100 & 100 & & \\
\hline \multirow[b]{2}{*}{ Hinundayan } & Sargassum & 0 & 0 & 100 & 100 & \multirow[b]{2}{*}{100} & \multirow[b]{2}{*}{1} \\
\hline & $\begin{array}{l}\text { Other } \\
\text { Features }\end{array}$ & 0 & 0 & 100 & 100 & & \\
\hline \multirow[b]{2}{*}{ Island } & Sargassum & 0 & 0 & 100 & 100 & \multirow[b]{2}{*}{100} & \multirow[b]{2}{*}{1} \\
\hline & $\begin{array}{l}\text { Other } \\
\text { Features }\end{array}$ & 0 & 0 & 100 & 100 & & \\
\hline
\end{tabular}

\begin{tabular}{|c|c|c|c|c|c|c|c|}
\hline B. SE & TINEL 2 II & AGE I & URIN & DECI & MBER & & \\
\hline Region & Class & $\begin{array}{l}\text { EC } \\
(\%)\end{array}$ & $\begin{array}{l}\text { EO } \\
(\%)\end{array}$ & $\begin{array}{l}\text { PA } \\
(\%)\end{array}$ & $\begin{array}{l}\text { UA } \\
(\%)\end{array}$ & $\begin{array}{l}\text { OA } \\
(\%)\end{array}$ & KC \\
\hline \multirow{3}{*}{ Silago } & Sargassum & 0 & 6.4 & 93.6 & 100 & \multirow{3}{*}{99.98} & \multirow{3}{*}{0.98} \\
\hline & Clouds & 3.7 & 0 & 100 & 100 & & \\
\hline & $\begin{array}{l}\text { Other } \\
\text { Features }\end{array}$ & 0.01 & 0.01 & 99.99 & 99.99 & & \\
\hline \multirow[b]{2}{*}{ Hinunangan } & Clouds & 0 & 0 & 100 & 100 & \multirow[b]{2}{*}{100} & \multirow[b]{2}{*}{1} \\
\hline & $\begin{array}{l}\text { Other } \\
\text { Features }\end{array}$ & 0 & 0 & 100 & 100 & & \\
\hline \multirow{3}{*}{ Hinundayan } & Sargassum & 0 & 3.77 & 96.23 & 100 & \multirow{3}{*}{99.99} & \multirow{3}{*}{0.98} \\
\hline & Clouds & 0 & 0 & 100 & 100 & & \\
\hline & $\begin{array}{l}\text { Other } \\
\text { Features }\end{array}$ & 0 & 0 & 100 & 100 & & \\
\hline \multirow[b]{2}{*}{ Island } & Sargassum & 0 & 0 & 100 & 100 & \multirow[b]{2}{*}{100} & \multirow[b]{2}{*}{1} \\
\hline & $\begin{array}{l}\text { Other } \\
\text { Features }\end{array}$ & 0 & 0 & 100 & 100 & & \\
\hline
\end{tabular}

Results from both satellite images show that the coast of Silago and Hinundayan are predominantly covered with Sargassum except in the Poblacion areas in Silago and An-An in Hinundayan (Figure $5 \& 6$ ). In addition, the eastern coast of San Pedro and San Pablo are largely covered with Sargassum. In contrast, the coast of Hinunangan is barely covered by the seaweed.

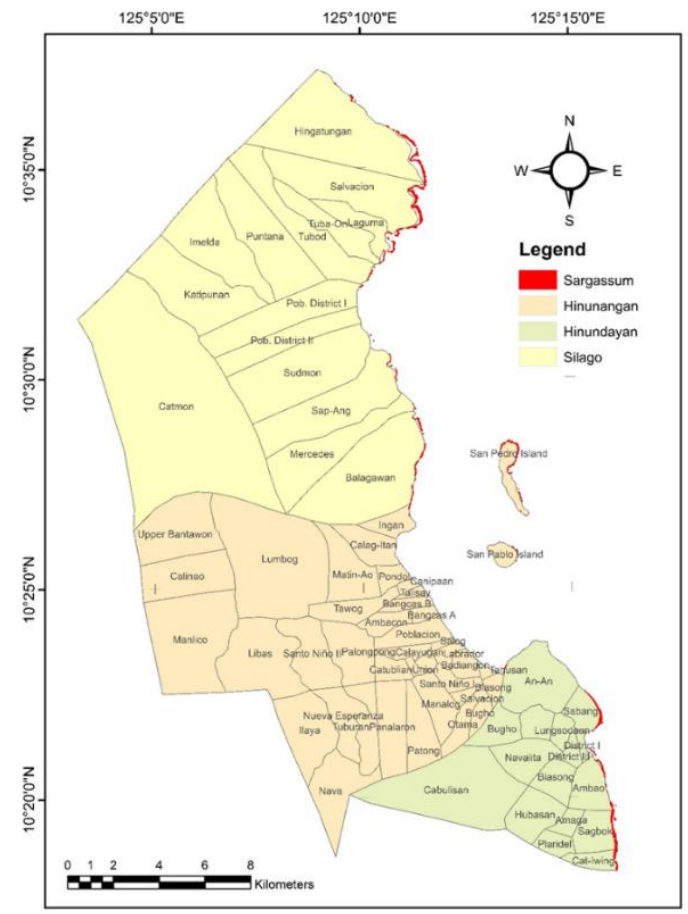

Figure 5. Sargassum map from classification of Sentinel 2 May image

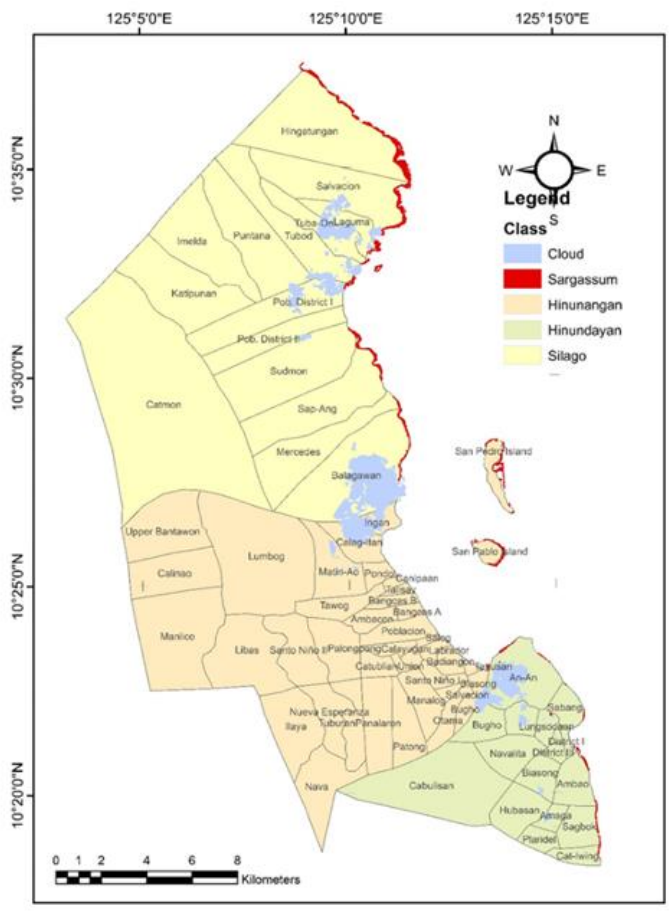

Figure 6. Sargassum map from classification of Sentinel 2 December image

Histograms of both NDVI point datasets were plotted to determine the frequency of its NDVI values. Point dataset of May Sentinel has a normal distribution of values with standard deviation of 0.064521 (Figure 7). This indicates that most of the NDVI values are within its mean. Values within the peak of its histogram are spread evenly over the study area. Hence, Sargassum health within the study area are likely the same. On 
the other hand, December Sentinel shows a bimodal distribution of values with standard deviation of 0.20177 . This indicates that there is quite a number of lower and higher NDVI values as shown in Figure 8 and 9. Thus, Sargassum health in December Sentinel are diverse. Values within the first peak of the histogram are mostly found in the coast of Silago while the second peak are equally distributed within the study area. Hence, low vegetation are mostly found in Silago but healthy vegetation cover are found evenly within the study area.

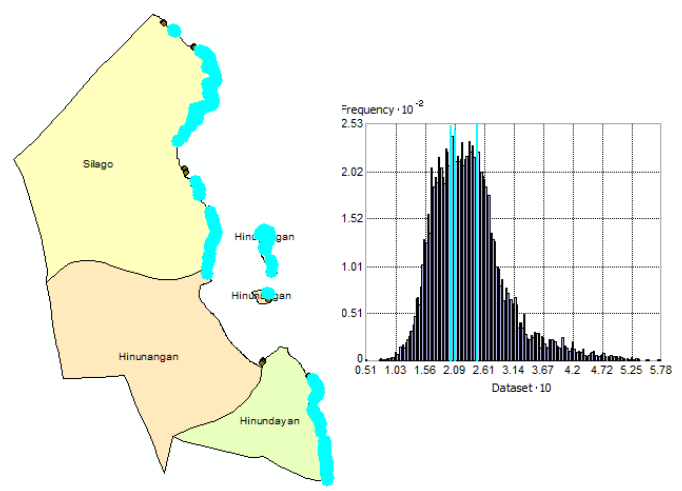

Figure 7. Frequency of NDVI values in May Sentinel image

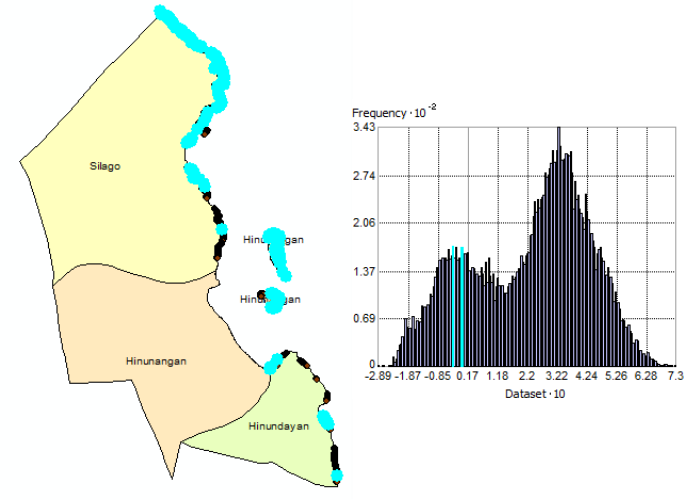

Figure 8. Location of low NDVI values in December Sentinel image

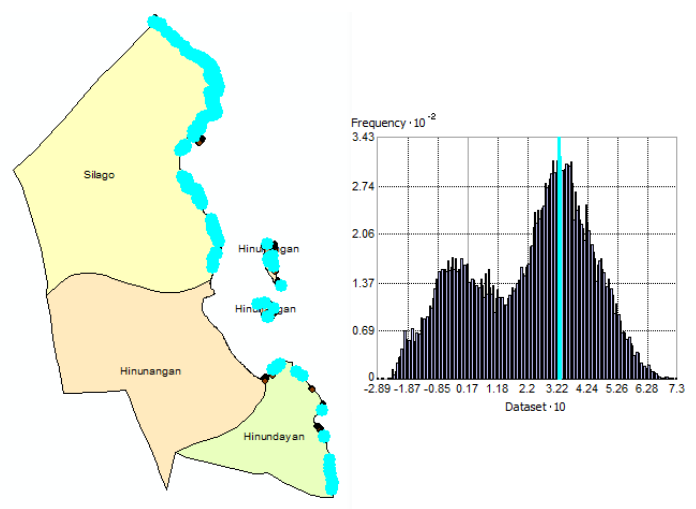

Figure 9. Location of high NDVI values in December Sentinel image
Tide level during the acquisition of May Sentinel was 0.61 meters above mean sea level, while in December Sentinel was 0.23 meters. The occurrence of higher tide in May resulted to relatively the same value of NDVI since most of the Sargassum observed were located near shore. Furthermore, Sargassum are in the Senescence stage around May. This stage is when changes that take place in a plant lead to death of cells, tissues and eventually the whole body (Horton 2019). On the other hand, December Sentinel obtained a more diverse NDVI values since wider Sargassum cover was observed. Though most of the seaweed are in its peak growth, there are still some that were still developing which contributed to a varied NDVI values.

To further understand the dataset, incremental spatial autocorrelation was done to determine the best threshold distance for cluster and outlier analysis. Determining the appropriate threshold distance ensures that most features have enough neighbors and will reflect maximum spatial autocorrelation. Unfortunately, the tool failed to execute when applied to the point dataset of December Sentinel. Z-score never peaked because the aggregation scheme of similar data is too coarse; hence, dataset was divided into groups or areas of smaller scales.

First area (A1) covered points in Silago while second area (A2) covered point dataset of both islands. Also, Hinundayan dataset and those located in the southern part of Hinunangan covered the third area (A3). Table 2 shows the threshold distance obtained from the Incremental Spatial Autocorrelation per area. These values indicate the corresponding distances where there is high intensity of spatial clustering of NDVI values per area. Hence, the values were used in the cluster and outlier analysis.

Table 2. Threshold distance (meters) from Incremental Spatial Autocorrelation

\begin{tabular}{|c|c|c|c|}
\hline Satellite Image & A1(m) & A2(m) & A3(m) \\
\hline May & \multicolumn{3}{|c|}{190} \\
\cline { 2 - 4 } & 330 & 100 & 80 \\
\hline \multirow{2}{*}{ December } & 540 & 130 & 380 \\
\hline
\end{tabular}

Inverse distance spatial relationship was used in the analysis for cluster and outlier. This type of spatial relationship deals with distance decay wherein closer features have higher weights and weights diminish as a function of distance. Areas that have significant cluster of high values (High-High) are represented by color red and cluster of low values (Low-Low) are in blue color. All other colors are outliers and not significant values. Cluster of high values (High-High) is more evident in December Sentinel (Figure 11). This conforms to the study of Trono and Lluisma (1990), Largo and Ohno (1992) and Montes (1993) stating that Sargassum reach peak growth and reproductive stage during the month of December. 


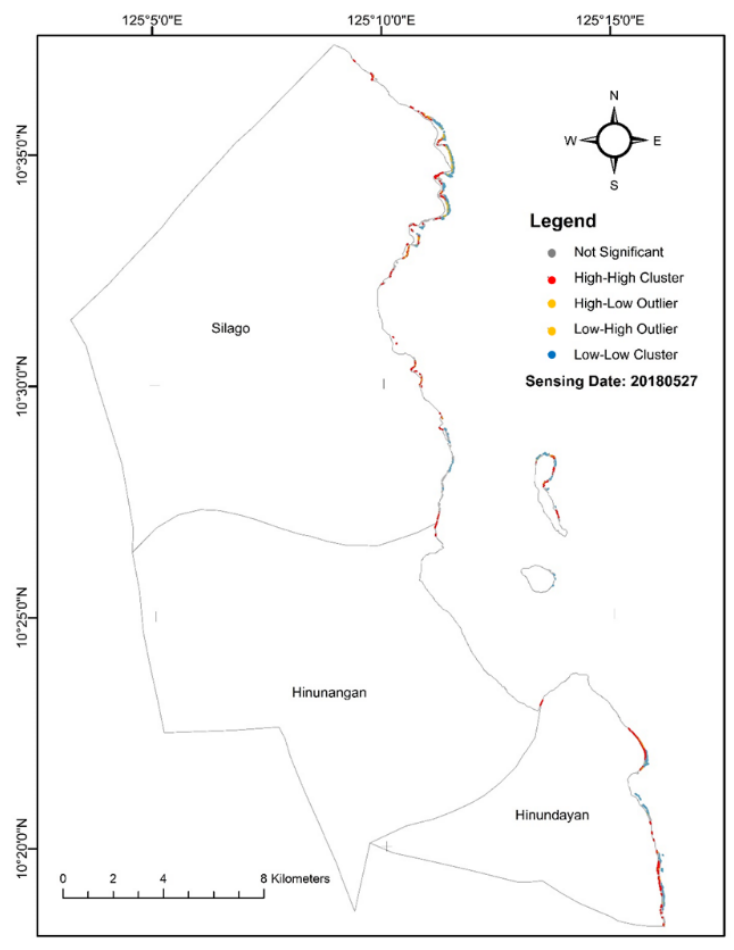

Figure 10. Cluster \& Outlier Analysis of Sargassum in May Sentinel image

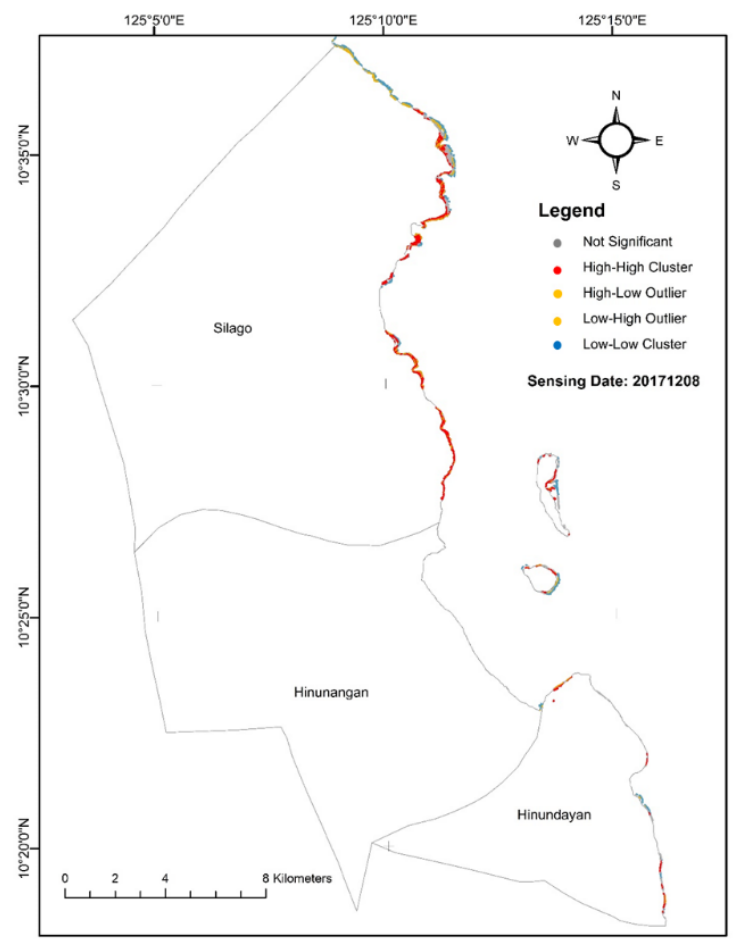

Figure 11. Cluster \& Outlier Analysis of Sargassum in December Sentinel image

\section{CONCLUSION}

The study revealed that the occurrence of Sargassum are found in the coast of Silago and in the eastern coasts of San Pablo and San Pedro islands. Moreover, patches of the seaweed are found in the coast of Hinundayan. However, healthy Sargassum or cluster of high NDVI values are more evident in the coast of Silago during December. It was also found out through field verification that these seaweeds are attached in rocky substrates and located near shore.

Sentinel-2, a high resolution and free satellite imagery can be used for coastal resource mapping specifically for Sargassum.

Hence, the results can be used as a tool in the implementation of FAO 250-2 series of 2017. This will guide farmers and the Department of Agriculture to manage Sargassum resources in the area and in the other coastal areas in the Philippines.

\section{ACKNOWLEDGEMENTS}

The study was funded by the Department of Science and Technology (DOST) through the Engineering Research and Development for Technology (ERDT) scholarship for graduate students in the University of the Philippines, Diliman.

I would also like to thank Dr. Humberto Montes Jr. and his Research Assistants from the Marine Laboratory, Department of Marine Biology, Visayas State University for assisting during field verification.

\section{REFERENCES}

\section{Journals:}

Baweja, P., Kumar, S., Sahoo, D. \& Lavine, I. (2016). Chapter 3-Biology of Seaweed. Seaweed in Health and Disease Prevention, 41-106. Academic Press. doi: 10.1016/C2014-002206-X

Belsher, T., Meinesz, A., Payri, C. \& Ben Moussa, H. (1990). Contribution of SPOT satellite to the knowledge of the coral reef ecosystems. The marine vegetation of Moorea-Island, French-Polynesia. Oceanol. Acta. 13: 513-524

Fulton, C., Depczynski, M., Holmes, T., Noble, M., Radford, B., Wernberg, T., \& Wilson, S. (2014). Sea temperature shapes seasonal fluctuations in seaweed biomass within the Ningaloo coral reef ecosystem. Limnology and Oceanography, 156-166. doi: 10.4319/lo.2014.59.01.0156

Gower, J \& King, S. (2011). Distribution of floating Sargassum in the Gulf of Mexico and the Atlantic Ocean mapped using MERIS. International Journal of Remote Sensing, 32, 1917-1929. doi: 10.1080/01431161003639660

Gower, J., Young, E. \& King, S. (2013). Satellite images suggest a new Sargassum source region in 2011. Remote Sensing Letters, 4, 764-773. doi: 10.1080/2150704X.2013.796433

Mattio, L., Dirberg, G., Payri, C.E. \& Andréfouët, S. (2008). Diversity, biomass and distribution pattern of Sargassum beds in the South West lagoon of New Caledonia (South Pacific). J.Appl.Phycol.20: 811-822. doi: 10.1007/978-1-4020-9619$8 \_45$

Noiraksar, T., Sawayama, S., Phauk, S., Komatsu, T. (2014). Mapping Sargassum beds off the coast of Chon Buri Province, Thailand, using ALOS AVNIR-2 satellite imagery. Botanica Marina, 57(5), 367-377. doi: 10.1515/bot-2014-0015 
Siddiqui, M.D. \& Zaidi, A. (2015). Worldview-2 and Landsat 8 Satellite Data for Seaweed Mapping along Karachi Coast. Pakistan Journal of Engineering, Technology \& Science (PJETS), Vol 5, No 2, 134-151. doi: 10.22555/pjets.v5i2.920

Tamayo, J. \& Del Rosario, E. (2014). Chemical Analysis and Utilization of Sargassum sp. as Substrate for Ethanol Production. Iranica Journal of Energy \& Environment, 202208. doi: 10.5829/idosi.ijee.2014.05.02.12

Wang, M. \& Hu, C. (2016). Mapping and quantifying Sargassum distribution and coverage in the Central West Atlantic using MODIS observations. Remote Sensing of Environment, 183, 350-367. doi: 10.1016/j.rse.2016.04.019

\section{Other Literature:}

Adet, L., Ragatoa, S.D., Sanou, C.L., Meminvegni, G. \& Sidibe, M. (2018). Mapping Sargassum fluorescence distribution on Nigerian sea

Congedo, L. (2016). Semi-Automatic Classification Plugin Documentation

Dorothy, R., Joany, R.M., Rathish, R.J., Prabha, S.S. \& Rajendran, S. (2015). Image Enhancement by Histogram equalization.

Hou, J. \& Jin, Y. (2005). The Healing Power of Chinese Herbs and Medicinal Recipes. New York: Haworth Press, Inc.

Montes Jr., H. (1993). Temporal Distribution and Phenology of Sargassum population in Maysolong Reef, Eastern Philippines.

Trono Jr., G.C. (1990). Seaweed Resources in the Developing Countries of Asia: Production and Socio-Economic Implications. Culture and use of algae in Southeast Asia: Proceedings of the Symposium on Culture and Utilization of Algae in Southeast Asia, Tigbauan, Iloilo, Philippines, 1-7.

\section{Websites:}

Humboldt State Geospatial Online (2019). Introduction to Remote Sensing. Retrieved from http://gsp.humboldt.edu/OLM/Courses/GSP_216_Online/less on6-1/supervised.html

ESRI (2018). Cluster and Outlier Analysis (Anselin Local Moran's I) Retrieved from http://desktop.arcgis.com/en/arcmap/10.3/tools/spatialstatistics-toolbox/cluster-and-outlier-analysis-anselin-localmoran-s.htm 